\title{
QUANDO O CORPO INDECIDIVEL NÃO TEM VEZ: INTERSEXUALIDADE E PRÁTICAS MÉDICAS NA FRANÇA DOS SÉCULOS XIX EXX
}

\author{
WHEN THE UNDECIDABLE BODY HAS NO PLACE: INTERSEXUALITY AND MEDICAL PRACTICES IN FRANCE \\ OF THE XIX AND XX CENTURIES
}

\section{RESUMO}

Neste artigo iremos abordar o corpo intersexual investigado e controlado pelas práticas médicas na França dos séculos XIX e XX. A partir do recorte de gênero, veremos como os corpos de sexo ambíguo sofreram inúmeras intervenções porque apresentavam uma estrutura em oposição aos modelos normativos. Através da análise de documentos médicos que registram casos de intersexualidade, veremos como o saber médico do século XIX e primeira metade do século XX buscou adequar tais corpos ao binarismo homem-mulher, muitas vezes através de cirurgias mutiladoras.

Palavras-chave: Corpo. Gênero. Intersexualidade. Medicina. França.

\begin{abstract}
In this article we will address the intersex body investigated and controlled by medical practices of the nineteenth and twentieth centuries in France. From the gender clipping, we will see how ambiguous sex bodies underwent numerous interventions because they presented a structure in opposition to normative models. Through the analysis of medical documents that record cases of intersexuality, we will see how medical knowledge of the nineteenth century and much of the twentieth century sought to adapt such bodies to man-woman binarism, often through mutilating surgeries.
\end{abstract}

Keywords: Body. Gender. Intersexuality. Medicine. France.

\section{Introdução}

O termo "hermafrodita" foi usado desde a antiguidade na cultura ocidental para designar os corpos que possuíam ao mesmo tempo os sexos feminino e

\footnotetext{
Rejane Lopes Rodrigues

Professora de Filosofia do Instituto Federal do Rio de Janeiro (IFRJ). Doutora em Memória Social pela Universidade Federal do Estado do Rio de Janeiro. lopes.rejane@gmail.com.

Francisco Ramos de Farias

Professor associado da Universidade Federal do Estado do Rio de Janeiro, Departamento de Fundamentos da Educação e Programa de Pós-Graduação em Memória Social. Doutor em Psicologia. Bolsista de Produtividade em Pesquisa 2. Atualmente é consultor Ad Hoc da Fundação de Amparo a Pesquisa do Estado do Rio de Janeiro (FAPERJ). framosdefarias@gmail.com.
} 
masculino, bem como os sujeitos de sexo ambíguo. Na virada do século XX para o século XXI, no entanto, o termo "hermafrodita" foi sendo pouco a pouco substituído pelo termo "intersexo". Segundo Machado (2008), o termo "intersexualidade" foi usado pela primeira vez na esfera médica em 1917, fazendo referência a uma gama de ambiguidades sexuais, incluindo o que era antes conhecido como "hermafroditismo". Esta questão nem sempre foi regulada pela esfera médica. Segundo Anne FaustoSterling (200o), até o início do século XIX, as decisões envolvendo o estatuto das pessoas intersex estavam a cargo da esfera jurídica. Nos anos de 1990, essa denominação foi apropriada também pelos ativistas políticos intersex para designar as pessoas que nascem com corpos que não se encaixam naquilo que entendemos por corpos masculinos ou femininos. Em 1993, é fundada a ISNA - Intersex Society America por pessoas que sofreram as cirurgias de ressignificação sexual quando crianças e que passaram a defender que os órgãos sexuais intersexuais de recémnascidos não devessem ser operados, a menos que colocassem em risco a saúde da criança. No mesmo ano, o lançamento de The five sexes: why male and female are not enough (Anne Fausto-Sterling: 1993), torna-se um marco para esta discussão. Neste artigo, a autora demonstra que a medicina utiliza o termo intersex para três subgrupos que misturam características masculinas e femininas: 1) Os chamados "hermafroditas verdadeiros", que ela chama de "hermes", que possuem um testículo e um ovário; 2) Os "pseudo hermafroditas masculinos", que ela chama de "mermes", que tem testículos e alguns aspectos da genitália feminina, mas não ovários; e 3) Os "pseudo hermafroditas femininos", que ela chama de "fermes", que tem ovários e alguns aspectos da genitália masculina, mas lhes falta testículos. Com isso, acrescentando-se aos já tradicionais sexos feminino e masculino os três intersexos, Anne Fausto-Sterling abre espaço para argumentar que o sexo é um continuum vasto e infinitamente maleável que desafia as limitações, mesmo que consideremos apenas cinco categorias. Como afirma Gaudenzi (2018: 4),

Na década de 1990, a naturalidade dos binarismos começou a ser questionada por pesquisadoras dos estudos de gênero e da ciência. Alguns ativistas se declararam contrários à realização da "correção" em qualquer momento da vida, e se aproximaram da analítica queer ao rechaçarem categorias binárias de classificação e normalização do comportamento sexual. Fundamentando-se na visão foucaultiana pós-identitária e fragmentada em relação ao pensamento hegemônico sobre a sexualidade, qual seja, identitário e binário, colocaram em xeque as formas correntes de compreensão das identidades sociais no mesmo período em que a problemática dos intersexuais se tornou socialmente visível.

De acordo com Machado (2008), a nomenclatura “intersex" e as categorias de "hermafroditismo" e "pseudo-hermafroditismo" foram questionadas recentemente no domínio médico com a publicação, em agosto de 2006, do chamado "Consenso de 
Chicago", no qual foi proposta a utilização do termo "Disorders of Sex Development (DSD)" no lugar de "Intersex" ou "Estados Intersexuais". O novo termo baseia-se no cariótipo e não mais nas gônodas, remetendo ao domínio da genética, da embriologia e da biologia molecular. Com isso, afasta-se de expressões mais compartilhadas pelo senso comum (como hermafroditismo) ou pelo ativismo político (como intersex) e aproxima-se de códigos mais "técnicos", buscando inviabilizar o uso de categorias classificatórias morais e/ou identitárias, associando essas últimas a um caráter pejorativo. Inaugura-se, assim, no campo da biomedicina, um período em que todo um arsenal endocrinológico e cirúrgico vai sendo cada vez mais utilizado nas práticas médicas no que se refere aos sujeitos intersexuais.

Pino (2007) destaca que em poucos casos a intersexualidade causa danos à saúde. A intersexualidade não é uma doença, mas sim um estigma social: uma condição de não conformidade física com os critérios culturalmente definidos de normalidade corporal. A experiência intersexual levanta dilemas que não são fáceis de resolver. Por um lado, há indivíduos organizados que reivindicam maior autonomia para gerir os seus corpos e lutam para acabar com certas práticas médicas e saberes científicos que marcam os seus corpos e suas vidas de maneira irreversível. Por outro, há uma lógica social e cultural que nega reconhecimento social àqueles que não são identificados com os ideais normativos do sexo binário. Tal lógica perpassa todos os corpos, mas se radicaliza no caso dos corpos intersexuais, pois são indivíduos que nascem com corpos diferenciados, aos quais não se atribui reconhecimento como um corpo possível. Os indivíduos que não se conformam às regras vivem em "zonas de abjeção", lugares nos quais sua própria humanidade é contestada.

Fazendo uma breve análise da história da intersexualidade, ainda segundo Pino (2007), podemos afirmar que ela é comumente descrita em três grandes períodos: 1) A “era das gônodas", que data de meados do século XIX e vai até os anos de 1950 e caracteriza-se pelo início das classificações médicas sobre os variados tipos de "hermafroditismo". É o período em que os critérios classificatórios baseavam-se na presença simultânea tanto das gônodas masculina quanto feminina; 2) A "era cirúrgica”, que tem início na década de 1950 e tem seu fim por volta dos anos de 1980. É o período em que são realizadas as primeiras cirurgias de ressignificação sexual.

Inicia-se nos Estados Unidos quando John Money, que veio a ser um dos maiores especialistas em intersexualidade, afirma que o sexo biológico não determina a identidade sexual dos indivíduos (de gênero e sexualidade), sendo passível de (re) construção; e 3) A "era do consenso", no qual o sexo a ser designado e decidido em colaboração com uma equipe multidisciplinar e com a ajuda dos pais. Este período teve início quando as pessoas que sofreram as primeiras cirurgias quando crianças passaram a contestá-las no final da década de 1980. Os procedimentos, destinados a criar "corpos normais", criavam muitas vezes corpos traumatizados, mutilados, sem sensibilidade e com perdas de funções. Importante ressaltar que a medicina não é a grande vilã da história, mas sim parte de uma ordem social onde o corpo

1 Segundo Machado (2008), tem em sido traduzido para o português como "Anomalias do Desenvolvimento Sexual (ADS)” ou ainda “Distúrbios do Desenvolvimento Sexual (DDS)”. 
é identificado e validado a partir do seu gênero. E também que as cirurgias devem ser colocadas como uma escolha e não uma imposição: algumas pessoas podem se opor às cirurgias, outras, entretanto, podem reivindicar essas mesmas cirurgias para tornarem suas vidas possíveis de serem vividas.

Em 1972, John Money publica com Anke Ehrhardt a obra Man E Woman, Boy $\mathcal{E}$ Girl: Gender Identity from Conception to Maturity, em que relata o caso de um menino de dois anos tratado no hospital da Universidade John Hopkins, de acordo com os métodos utilizados em casos de intersexualidade. Neste caso, o menino não foi diagnosticado como intersexual. Por ocasião de uma circuncisão aos 9 meses de idade, que o deixou sem pênis, Money considerou que a melhor solução para resolver o problema seria "tranformá-lo" em uma menina. Segundo ele, um menino não poderia ter uma identidade sexual "normal" sem um pênis. Sendo assim, depois de uma castração e um tratamento hormonal, "Bruce” tornou-se "Brenda' um pouco antes dos 3 anos de idade. Segundo Dorlin (2008), Money teria utilizado Bruce/ Brenda como cobaia: ele teria realizado uma das primeiras cirurgias de mudança de sexo e, com isso, demonstrado a flexibilidade da divisão sexo/gênero. É interessante ressaltar que, embora seja o período em que o sexo começou a ser pensado como algo passível de modificação, a natureza e a binaridade do sexo não foram colocadas em xeque, pois os sujeitos intersexuais eram considerados frutos de desenvolvimento anormal e necessitavam de tratamento para se tornar homens ou mulheres.

Antes da análise dos documentos que serão apresentados neste trabalho, é importante entender como tais práticas médicas foram orientadas a partir de um modelo de sexo baseado no dimorfismo sexual. Em Inventando o sexo. Corpo e gênero dos gregos a Freud, Laqueur (2001) nos mostra através de uma análise histórica como, a partir do século XVIII, o antigo modelo do sexo único - homem como modelo e mulher como versão degenerada do homem - deu lugar a um novo modelo de dimorfismo radical, de divergência biológica. Segundo o autor, durante milhares de anos acreditou-se que as mulheres tinham a mesma genitália que os homens, só que a delas ficaria dentro do corpo e não fora. A partir do final do século XVII e ao longo do século XVIII, no entanto, a ciência passou a considerar as categorias "masculina" e "feminina” como sexos biológicos opostos e incomensuráveis. Não só os sexos passaram a ser diferentes, como também todos os aspectos concebíveis do corpo e da alma, em todos os seus aspectos físicos e morais. O interesse em buscar evidências de dois sexos distintos, diferenças anatômicas e fisiológicas concretas entre o homem e a mulher, no entanto, só ocorreu quando essas diferenças se tornaram politicamente importantes. As descobertas científicas não justificaram sozinhas a criação do modelo dimórfico dos sexos. A nova biologia, em sua busca pelas diferenças fundamentais entre os sexos, emergiu precisamente quando as fundações da velha ordem social foram abandonadas uma vez por todas. Segundo Laqueur (Laqueur, 2001: 171):

As reivindicações universais por liberdade e igualdade humana durante o Iluminismo e as promessas da Revolução Francesa - que a humanidade em todas as suas relações sociais e culturais podia 
ser regenerada, que as mulheres podiam atingir não só liberdades civis como também pessoais, que a família, a moralidade e as relações pessoais podiam ser renovadas - fizeram surgir não só um feminismo novo e genuíno como também um novo tipo de antifeminismo, um novo medo das mulheres, e fronteiras políticas que criaram fronteiras sexuais. A criação de uma esfera pública burguesa, em outras palavras, levantou com violência a questão de qual sexo deveria ocupá-la legitimamente. E em todo lugar a biologia entrava no discurso. Obviamente, os que se opunham a um crescente poder civil e privado das mulheres - na grande maioria homens articulados - criaram a evidência da inadequação física e mental das mulheres para esses avanços: seus corpos não eram adequados aos espaços que a revolução abrira.

Desta forma, no final do século XIX, as demandas políticas imediatas para a criação de sexos biologicamente distintos e o papel específico da ciência nesse empreendimento já estão especialmente claros. A ciência e a filosofia trabalharam para produzir um pensamento que justificasse a tradicional desigualdade entre homens e mulheres de modo a torná-la compatível com os ideais igualitários da Revolução Francesa. Não se podia mais justificar socialmente a desigualdade. Ela agora se assentava na natureza e a ciência era a ferramenta legítima para evidenciála. Enquanto as mulheres eram mantidas atreladas à natureza, os homens se beneficiavam do seu estatuto de seres da razão. De uma diferença quantitativa, de graus, a descrição da diferença passou a ser qualitativa, e os dois sexos passaram a ser descritos pelo padrão da oposição e não mais da hierarquia. Desta forma, Laqueur (2001) mostra com evidências históricas que quase tudo que se queira dizer sobre sexo já contém em si uma reivindicação sobre o gênero. $O$ sexo, tanto no mundo de sexo único como no de dois sexos, é situacional; é explicável apenas dentro do contexto da luta sobre gênero e poder. Com isso, justifica-se a preocupação dos médicos pela busca do "verdadeiro" sexo. Se antes, para os hermafroditas, a questão não era "a que sexo eles pertenciam realmente", mas a que gênero a arquitetura de seus corpos mais se ajustava, no século XIX o comportamento é irrelevante. A questão do sexo passa a ser biológica, uma questão de fato, que pode e deve ser solucionada pelo exame anatômico e fisiológico da pessoa em questão.

A partir destas perspectivas teóricas, analisaremos neste artigo casos de intersexualidade que ocorreram na França do século XX: o primeiro, intitulado Hermaphrodite gynandroïde parfaite: une jeune fille dans une situation diffícile, publicado em 1933 por Louis Ombrédanne (1871-1956), célebre cirurgião plástico e pediatra francês, e o segundo, uma tese de doutorado intitulada Le concept de troisieme genre: a propos de la décision d'um changement de sexe chez un sujet de 18 ans hermaphrodite vrai, defendida em 1984 por uma médica psiquiatra chamada Patricia Blanche Garel, que acompanhou o caso. Os documentos aqui analisados foram pesquisados na Biblioteca Nacional da França, em Paris, e constituem os casos mais significativos encontrados em seus arquivos. Antes, faremos uma breve análise 
do caso Herculine Barbin, ocorrido no final do século XIX e cujo diário foi publicado por Foucault, em 1980, com o título Herculine Barbin: o diário de um hermafrodita. Também analisaremos uma série de nove fotos realizadas pelo fotógrafo francês Félix Nadar, provavelmente o primeiro a registrar um corpo intersexual ainda no final do século XIX.

A escolha pela pesquisa nos arquivos franceses não ocorreu por acaso. Houve, em França, um grande interesse por parte da comunidade médica pelo assunto. Isso se deve às transformações políticas ocorridas a partir do século XVIII: é neste período, segundo Houbre (2009), que a França elabora ao mesmo tempo uma reflexão sobre a identificação dos indivíduos e técnicas que a colocam em prática, como o estado civil e o passaporte, por exemplo. É também neste período que os médicos conceitualizam e promovem a diferenciação dos sexos, consolidada pelo Estado a partir do registro do recém-nascido, que se estabelece exclusivamente a partir do sexo masculino ou feminino. O código napoleônico de 1804, que certificava as regras do estado civil de um indivíduo como princípio da desigualdade dos sexos, testemunha essas evoluções e inaugura o século da sistematização do disformismo sexual. Com isso, o meio médico adquire toda a sua potência social, impõe uma economia normativa estrita para tudo o que diz respeito ao corpo, ao sexo e à sexualidade. Tal elaboração normativa esbarra, no entanto, na existência dos indivíduos intersexuais: eles representam para os médicos um sexo impossível, um corpo dissidente, singularizado por um emaranhado do masculino e do feminino, que eles tentam desembaraçar através da busca pelo "verdadeiro" sexo. Com isso, veremos como a pesquisa sobre a identidade sexual, cada vez mais minuciosa na França deste período, foi responsável pelo desenvolvimento de "cirurgias corretivas" mutiladoras, muitas vezes impostas aos indivíduos intersexuais. Tais cirurgias foram usadas, muitas vezes, como instrumento privilegiado no processo de normatização desses "corpos indecidíveis".

\section{O discurso médico sobre a intersexualidade na França do século XIX}

Em $O$ verdadeiro sexo, Foucault (2010) afirma que um longo tempo se passou até que se postulasse que um hermafrodita deveria ter um único e "verdadeiro sexo". Na Idade Média, por exemplo, as regras do direito (canônico e civil) eram muito claras em relação a isso: eram chamados hermafroditas aqueles nos quais se justapunham, segundo proporções que podiam ser variáveis, os dois sexos. Neste caso, cabia ao pai ou padrinho estabelecer, no momento do batismo, o sexo que deveria ser mantido. Porém, mais tarde, na vida adulta, quando chegasse o momento de se casar, o hermafrodita era livre para decidir se queria ser sempre do sexo que lhe haviam atribuído, ou se preferia o outro. $\mathrm{O}$ único imperativo era manter até o fim de seus dias aquele que, então, havia declarado, sob pena de ser condenado por infringir as 
leis. Mais tarde, na Idade Moderna, do ponto de vista médico, não se tratou mais de reconhecer a presença dos dois sexos justapostos ou misturados, nem de saber qual dos dois prevalecia sobre o outro, mas sim de decifrar qual era o "verdadeiro sexo" que se escondia sob aparências confusas. O médico passa a ter a obrigação de despir as anatomias enganadoras e reencontrar o único "verdadeiro sexo". Do ponto de vista do direito, isso implicava evidentemente o desaparecimento da livre escolha. Não cabe mais ao indivíduo decidir o sexo ao qual ele deseja pertencer jurídica ou socialmente, mas sim ao perito dizer que sexo a natureza escolheu para ele, e ao qual, consequentemente, a sociedade deve lhe exigir restringir-se.

A obra Herculine Barbin: o diário de um hermafrodita (Foucault, 1982) revela as memórias de Adélaïde Herculine Barbin, comumente chamada de Alexina, nascida em 1838, na França. Criada como uma moça pobre, em um meio quase que exclusivamente feminino e profundamente religioso, foi reconhecida já na idade adulta como um "verdadeiro" rapaz. Obrigada a trocar o sexo legal, após um processo jurídico e uma modificação do seu estado civil, foi incapaz de se adaptar à sua nova identidade e acabou se suicidando. A obra, organizada e com introdução do próprio Foucault, também reúne os relatórios do doutor Chesnet, primeiro médico que examinou e constatou o hermafroditismo de Alexina e do doutor Goujon, médico que fez a sua autópsia. Há também um breve relato feito pelo célebre médicolegista do século XIX Tardieu sobre o caso, publicado na segunda parte da sua obra Question médico-légale de l'identité dans ses rapports avec les vices de conformation des organes sexuels (1874). A primeira parte do volume foi publicado nos Annales d'hygiène publique, em 1872.

Os textos encontrados em Herculine Barbin: o diário de um hermafrodita, constituem um documento que retrata a estranha obsessão da medicina e da justiça pelo "verdadeiro sexo" no século XIX. Adélaïde Herculine Barbin, ou ainda Abel Barbin, foi um desses personagens infelizes da caça à identidade. As memórias da sua vida, Alexina escreveu quando já havia sido descoberta e estabelecida a sua nova identidade. Sua "verdadeira” e "definitiva” identidade. Quando redige as suas memórias não está longe de seu suicídio. Em seus momentos mais dramáticos, ela² demonstra o quanto os saberes e poderes que transformaram a sua identidade foram responsáveis pela destruição de sua vida.

Tardieu, o célebre médico-legista do século XIX, recebeu os manuscritos completos das memórias de Adélïde Herculine Barbin, então já vivendo como Abel Barbin, diretamente das mãos do médico que atestou o óbito e fez a autópsia. Entretanto, publicou apenas a parte que lhe parecia importante: negligenciou as memórias dos últimos anos de Alexina porque, segundo ele, não passavam de "lamentos, recriminações e incoerências" (FOUCAULT, 1982). O que não foi publicado em sua obra Question médico-légale de l'identité dans ses rapports avec les vices de conformation des organes sexuels (1874), já citada nesta seção, perdeu-se para

2 Optei por referir-me a Adélïde Herculine Barbin neste trabalho sempre por "ela”, isto porque era com o gênero feminino que ela claramente se identificava. 
sempre. Nesta obra, Tardieu (Tardieu, 1874: 61-62) apresenta as memórias de Alexina da seguinte forma:

Veremos a vítima de tal erro, após vinte anos acostumada aos hábitos de um sexo que não é o seu, lutando com uma paixão que ignora-se a si mesma, sendo avisada, enfim, pela explosão de seus sentidos, ser devolvida ao seu verdadeiro sexo e ao mesmo tempo ao sentimento real de sua enfermidade física, levar a vida com desgosto e dar-lhe fim com o suicídio.

Este pobre infeliz, criado em conventos e internatos femininos até a idade de vinte e dois anos, aceito nos exames e possuidor de um diploma de professora, teve após dramáticas e comoventes circunstâncias seu estado civil modificado por um julgamento do tribunal de La Rochelle, e não pôde suportar a existência miserável que seu novo sexo incompleto lhe impôs. Certamente, nesse caso, as aparências do sexo feminino foram levadas às últimas consequências, mas apesar disso, a ciência e a justiça foram obrigadas a reconhecer o erro e a devolver esse jovem rapaz a seu sexo verdadeiro. ${ }^{3}$

O discurso sobre o "verdadeiro sexo" é uma constante em todos os relatórios médicos sobre o caso. O relatório de Chesnet (1982), o primeiro médico que examinou Alexina, por exemplo, já é nomeado Question d'identité. Vice de conformation des organes génitaux. Hypospadias. Erreur sur le sexe. O médico faz uma descrição dos órgãos sexuais dela no relatório e constata uma formação ambígua que, a princípio, não poderia identificá-la como pertencente ao sexo feminino ou ao masculino apenas.

Goujon, por sua vez, médico responsável pela autópsia de Alexina, descreve em Étude d'um cas d'hermaphrodisme bisexuel imparfait chez l'homme (1869) a mesma anatomia descrita no relatório de Chesnet, apenas com alguns acréscimos sobre os seus órgãos internos. Os novos acréscimos não são tão relevantes, sendo praticamente a repetição do que já havia sido observado externamente. Podemos verificar a seguir a explanação e os desenhos utilizados na obra de Goujon (1869):

3 On va voir la victime d'une semblable erreur, aprés vingt ans passés sous les habits d'un sexe qui n'est pas le sien, aux prises avec une passion qui s'ignore ele-même, avertie enfin par l'explosion de ses sens, puis rendue à son véritable sexe en même temps qu'au sentimento réel de son infirmité physique, prenant la vie em dégoût et y mettant fin le suicide.

Ce pauvre malheureux, élevé dans um couvent et dans des pensionnats de jeunes filles jusqu'à l'âge de vingt deux ans, admis aux examens et pourvu du deplôme d'institutrice, vit à la suíte des circonstances les plus dramatiques et les plus émouvantes son état civil réformé par un jugement du tribunal de La Rochelle, et ne put supporter l'existence misérable que son nouveau sexe incomplet lui impose. Certes, dans ce cas, les apparences du sexe féminin ont été poussées bien loin, et cependant la science et la justice furent contraentes de reconnaitre l'erreur et de rendre ce jeune homme à son sexe véritable. 
Figura 1

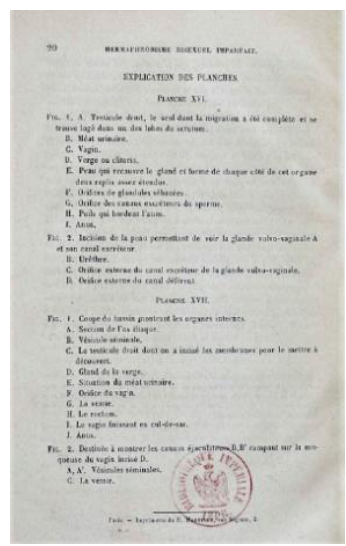

Fonte: Retirado de GOUJON, Étienne. Étude d'um cas d'hermaphrodisme bisexuel imparfait chez l'homme. Paris: Imprimerie de E. Martinet: 1869: 2o. Disponível em: http://gallica.bnf.fr/ ark:/12148/bpt6k64594407/f7.image. Acesso em: 18 set. 2017.
Figura 2

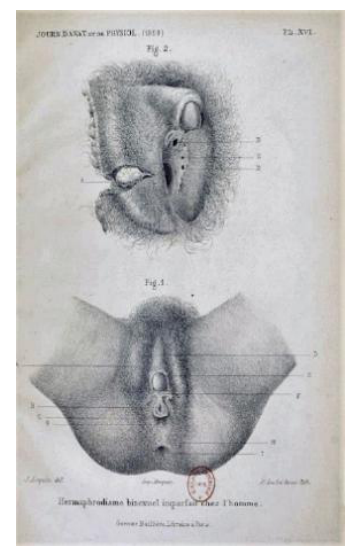

Fonte: Retirado de GOUJON, Étienne. Étude d'um cas d'hermaphrodisme bisexuel imparfait chez l'homme. Paris: Imprimerie de E. Martinet: 1869: 21. Disponível em: http://gallica.bnf.fr/ ark:/12148/bpt6k64594407/f7.image.

Acesso em: 18 set. 2017.

\section{Figura 3}

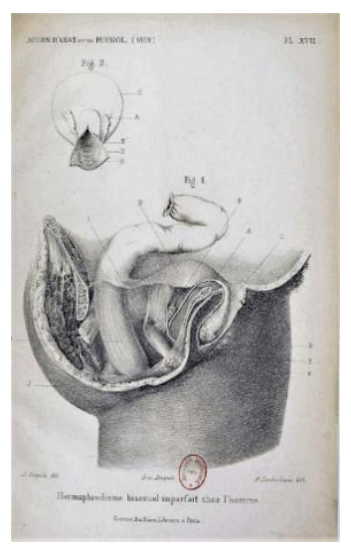

Fonte: Retirado de GOUJON, Étienne. Étude d'um cas d'hermaphrodisme bisexuel imparfait chez l'homme. Paris: Imprimerie de E. Martinet: 1869: 22. Disponível em: http://gallica.bnf.fr/ark:/12148/bpt6k64594407/f7.image. Acesso em: 18 set. 2017.

O mais interessante em seu relatório é como Goujon (1869) justifica o trágico destino de Alexina como tendo sido necessário para devolver-lhe o seu "verdadeiro sexo". Tal argumento é presença constante em seu texto, podendo ser ilustrado pelo seguinte trecho:

A autópsia que nós fizemos permitiu retificar o primeiro julgamento feito a respeito do sexo que perdurou durante a maior 
parte de sua vida, bem como confirmar a exatidão do diagnóstico que por último devolveu-lhe a seu verdadeiro lugar na sociedade.

Como podemos observar pelo que foi enunciado acima, o presente caso levanta diversas questões fisiológicas e médico-legais. A conformação dos órgãos genitais externos desse indivíduo lhe permitia, embora manifestamente fosse um homem, representar indistintamente o papel de homem ou mulher. ${ }^{4}$ (Goujon, 1869: 5)

Ora, se a conformação dos órgãos genitais de Alexina permitia representar indistintamente o papel de homem ou mulher, por que ela foi considerada manifestamente um homem? Por que um tribunal foi acionado para devolver-lhe o seu "verdadeiro lugar na sociedade"? Por fim, Goujon (1869) conclui que a solução encontrada para remediar determinados vícios de conformação designados sob o nome de hermafroditismo é a realização de cirurgias reparadoras. Cita alguns casos da época, entre eles o de um cirurgião que fez uma vagina artificial em uma paciente com "absoluto sucesso". Neste caso, como em todos os outros, não havia espaço para corpos ambíguos que fugiam do sistema binário de sexo.

Nas últimas décadas do século XIX, a fotografia científica se difunde enquanto um novo instrumento para os médicos. A fotografia passa a oferecer um apoio ao olhar, um suporte estável e descritível, imprescindível na apropriação do sujeito hermafrodita. É, inclusive, a pesquisa científica que legitima o nu fotográfico: a Revue photographique des hôpitaux de Paris, que compreendia sete volumes publicados entre 1869 e 1876 , por exemplo, era ilustrada com inúmeros nus totais como suporte para a descrição de algumas doenças. Importante ressaltar que nesta época a censura na França impedia a reprodução da nudez, bem como a "exposição para ostentação" da maior parte dos nus artísticos ou acadêmicos. Desde 1819, era definido como atentado aos bons costumes, toda fabricação, difusão ou exposição de uma obra de caráter licencioso, suscetível, inclusive, de processo judicial e de condenação. Mesmo assim as patologias autorizavam as tomadas mais ambiciosas e mais indiscretas, em grandes planos das partes mais íntimas do corpo.

Félix Nadar, célebre fotógrafo francês, provavelmente foi o primeiro fotógrafo a registrar um corpo intersexual, dando continuidade a uma longa tradição de representações visuais mais ou menos reais ou idealizadas dessas pessoas. Em janeiro de 1861, ele faz o depósito legal de um conjunto de nove fotografias que registra um caso de hermafroditismo, mas a autorização da sua difusão é limitada ao uso puramente científico. As fotografias, hoje conservadas na Biblioteca Nacional da

4 L'autopsie qu'on a pu faire a permis de rectifier le premier jugement qui avait été porté sur son sexe pendant la plus grande partie de as vie, et de confirmer l'exactitude du diagnostic qui l'avait en dernier lieu remis à as véritable place dans la societé.

D’après l'énoncé qui precede, on voit que le cas présent soulève plusieurs questions physiologiques et médico-légales. La conformation des organes génitaux externes de cet individu lui permetait, bien qu'il fût manifestement um homme, de jouer dans le coït indistinctement le rôle de l'homme ou de la femme. 
França, são organizadas em um portfólio segundo uma ordem progressiva. Em sua totalidade, esta progressão segue o desenrolar de uma consulta médica. Na primeira, o sujeito está em pé. A segunda mostra o tronco do sujeito e as seguintes o momento em que ele é colocado em uma mesa onde é examinado. A cabeça e as mãos de um médico testemunham a cena. As últimas mostram o momento em que as partes genitais do paciente estão cada vez mais próximas. Podemos verificar na última fotografia que os pelos do paciente foram retirados para permitir uma melhor visão da sua anatomia, conforme podemos verificar a seguir:

Figura 4

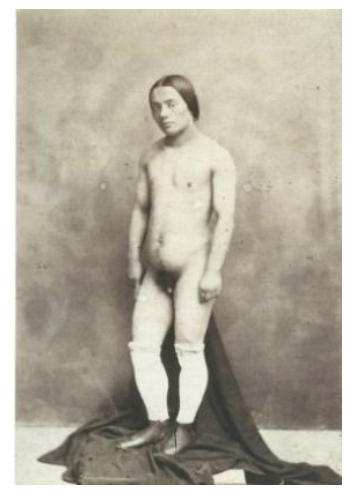

Fonte: Retirado de LE MENS, Magali \& NANCY, Jean-Luc. L'hermaphrodite de

Nadar. Nantes: Creaphis Éditions, 2009: I.

Figura 6

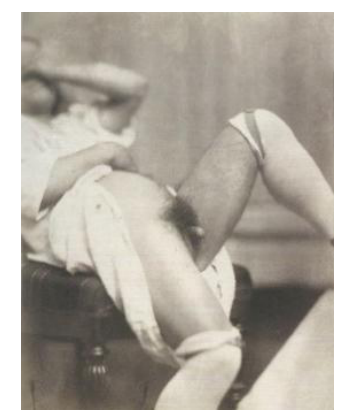

Fonte: Retirado de LE MENS, Magali \& NANCY, Jean-Luc. L'hermaphrodite de Nadar. Nantes: Creaphis Éditions, 2009: III.
Figura 5

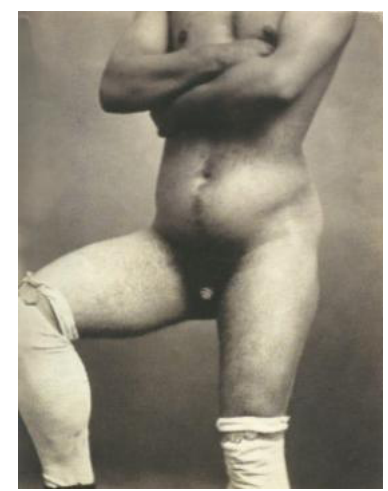

Fonte: Retirado de LE MENS, Magali \& NANCY, Jean-Luc. L'hermaphrodite de Nadar. Nantes: Creaphis Éditions, 2009: II. 
Figura 9

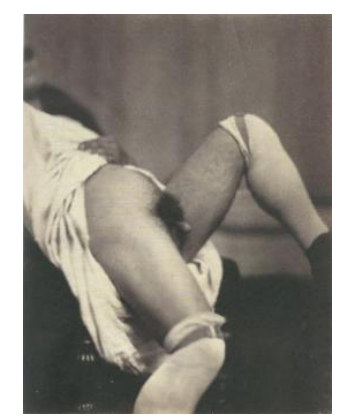

Fonte: Retirado de LE MENS, Magali \& NANCY, Jean-Luc. L'hermaphrodite de Nadar. Nantes: Creaphis Éditions, 2009: V.

Figura 10

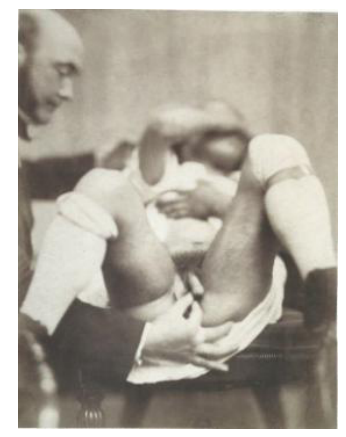

Fonte: Retirado de LE MENS, Magali \& NANCY, Jean-Luc. L'hermaphrodite de Nadar. Nantes: Creaphis Éditions, 2009: VII.
Figura 9

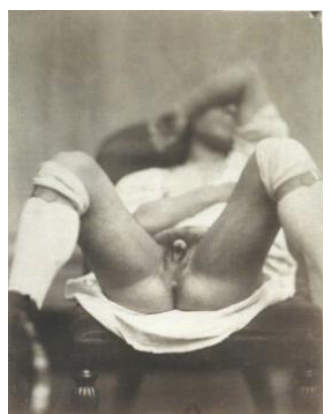

Fonte: Retirado de LE MENS, Magali \& NANCY, Jean-Luc. L'hermaphrodite de Nadar. Nantes: Creaphis Éditions, 2009:

VI.

\section{Figura 11}

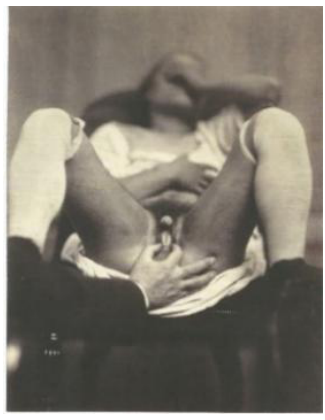

Fonte: Retirado de LE MENS, Magali \& NANCY, Jean-Luc. L'hermaphrodite de Nadar. Nantes: Creaphis Éditions, 2009: VIII.

Figura 12

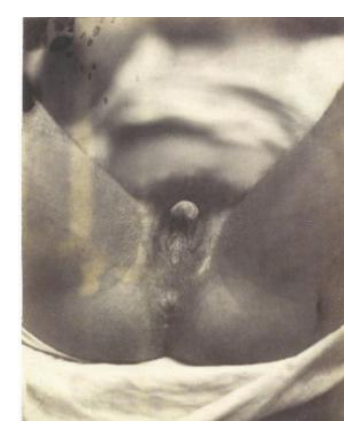

Fonte: Retirado de LE MENS, Magali \& NANCY, Jean-Luc. L'hermaphrodite de Nadar. Nantes: Creaphis Éditions, 2009: IX. 
As fotografias provavelmente foram executadas um pouco antes do seu depósito legal. Na obra L'hermaphrodite de Nadar (Le Mens \& Nancy, 2009), onde as imagens foram cuidadosamente analisadas, não há maiores informações sobre o sujeito fotografado ou o suposto médico que teria conduzido o ensaio fotográfico, bem como a origem e circunstâncias de sua feitura. Sabe-se apenas que Nadar era um importante retratista da época e que deve ter sido este o motivo pelo qual foi escolhido para realizar o trabalho. Nesta mesma época, outros casos de intersexualidade foram longamente e minuciosamente descritos pelos médicos. Como já vimos, a mudança de sexo de Herculine Barbin, por exemplo, ocorreu exatamente em julho de 186 o.

\section{Análise do documento Hermaphrodite gynandroïde parfaite: une jeune fille dans une situation diffícile, publicado em 1933.}

Mesmo considerando que a "era das cirurgias" em sujeitos intersexuais tenha seu marco histórico somente a partir da década de 1950, há relatos de cirurgias feitas ainda na primeira metade do século XX. Em Hermaphrodite gynandroïde parfaite: une jeune fille dans une situation diffícile, Ombrédanne (1933) opta por não realizar a cirurgia de correção na paciente, no momento ainda com 12 anos de idade, mas a opera mesmo assim para descobrir qual seria o seu verdadeiro sexo. As reflexões desenvolvidas por ele ao longo do texto são bastante reveladoras e nos mostram como o saber médico, legitimado em sua época como verdadeiro e inquestionável, lhe coloca muito mais dúvidas do que soluções no caso analisado. Ombrédanne inicia o seu relato contando a singular história de sua paciente: uma menina de 12 anos registrada com o nome de Camille-Nelly5 e que começou a desenvolver "um pênis verdadeiramente esplêndido para uma pessoa de 12 anos". O relato é ainda complementado pela fotografia a seguir, que mostra apenas o órgão sexual da moça.

Figura 13: Foto do órgão sexual da paciente de Ombrédanne, Camille-Nely.

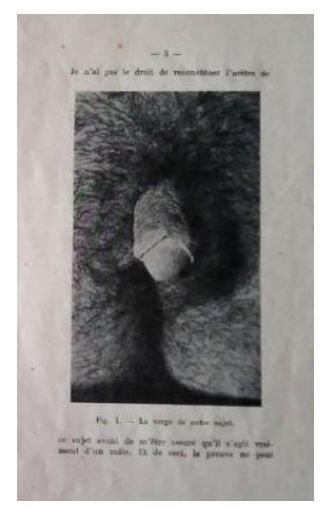

Fonte: Retirado de OMBRÉDANNE, Louis. Hermaphrodite gynandroîde parfaite: une jeune fille dans une situation difficile. Paris: Masson et Cle Éditeurs, 1933: 3.

5 Nos relatos encontrados em minha pesquisa, o nome "Camille" é muito encontrado em indivíduos intersexuais. Isso provavelmente acontecia porque o nome é considerado neutro na França. A própria Adélaïde Herculine Barbin, a Alexina, adota esse nome em suas memórias. 
A paciente teria sido examinada anteriormente por outro médico, que a diagnostica com uma hipospadia vulviforme ${ }^{6}$ e, consequentemente, como pertencendo ao sexo masculino. Este primeiro médico também encaminha a paciente para Ombrédanne para que ela seja submetida a uma cirurgia capaz de resolver tal malformação. Apesar de parecer um diagnóstico plausível, Ombrédanne não o aceita, partindo para uma investigação mais detalhada. No documento, endereçado aos seus alunos, ele afirma que o aspecto da paciente era realmente o de um menino: ombros largos, peito sem traços de seios, bacia estreita e desenvolvimento bem acentuado dos pelos do corpo: mesmo um menino de 12 anos não era normalmente tão peludo a este ponto. A foto realmente comprova a quantidade excessiva de pelos, semelhante ao corpo de um homem adulto. Ombrédanne (1993) descreve que, ao realizar um minucioso exame, não encontrou nenhum traço de testículos. Conclui, então, que não pode reconstruir a uretra da paciente sem estar seguro que ela (ou ele) pertence verdadeiramente ao sexo masculino. Como em quase todos os relatos de casos de sexo ambíguo, o texto alterna os pronomes pessoais "ele" e "ela" de forma aleatória.

Para resolver tal dúvida, Ombrédanne decide submeter a paciente a uma laparotomia (abertura cirúrgica da cavidade abdominal) para descobrir o seu "verdadeiro" sexo. Na cirurgia, ele não encontra nenhum traço de testículo, mas sim um pequeno útero de 3 centímetros e ovários tanto do lado direito quanto do lado esquerdo. Desta forma, a questão do sexo, organicamente falando, estava resolvida. O sexo da paciente foi determinado pelo médico através da presença de gônodas femininas em seu corpo. Depois disso ele encontra uma vagina de 9 centímetros cheia de muco: segundo ele, uma vagina longa, ampla e apta à penetração, que precisava apenas ser reconstruída em sua abertura, o que o médico realiza apenas com anestesia local. Após a descrição de tais intervenções cirúrgicas, muito mais detalhadas no documento original, obviamente, o texto encaminha-se para a parte mais interessante: as considerações sobre qual sexo legal a paciente deveria adotar, levando em conta os prós e contras de cada uma das duas opções.

Ombrédanne (1993) começa afirmando que nenhum tribunal, com a confirmação comprovada da existência de um útero e ovários e sem a presença de testículos, recusaria conceder a identidade feminina à sua paciente. No entanto, o pênis que ela apresenta é incompatível com a forma feminina. E além do pênis, todas as suas características físicas são compatíveis com um corpo masculino: seu peito plano e musculoso, seus membros fortes e o desenvolvimento impressionante de pelos, do umbigo até os joelhos. Desta forma, apresenta aos seus alunos as duas hipóteses possíveis, cada uma com as suas prováveis consequências para o contexto em que a criança vive. Ele também chama a atenção para o fato de que os pais precisam enviá-la para a escola por já possuir 12 anos e que, por serem pobres, não possuem condições de contratar uma professora particular.

6 A hipospadia é uma má-formação na uretra do menino, fazendo com que a urina saia através de uma abertura por baixo do pênis. No caso da hipospadia vulviforme, a bolsa escrotal bífida assume o aspecto de uma vulva. 
1. Primeira hipótese: ser registrado como menino. $\mathrm{O}$ que poderia acontecer com ele em uma escola de meninos? Ele já possui consciência de possuir uma vagina. E se ele tiver um "comportamento instável" e resolver "se servir" dela? Poderia engravidar? Ele possui um útero infantil, com baixa possibilidade de uma gravidez, mas não impossível. Afinal, existem mulheres com úteros minúsculos que se tornam mães. E o que acontecerá se lhe for dado uma educação escolar masculina e, aos 21 anos, quando for submetido a um conselho de revisão, for repentinamente considerado uma mulher? Não seria melhor já fazê-lo na idade de 12 anos, quando suas ideias sobre o futuro são infinitamente menos precisas? Mesmo se for liberado do serviço militar, ele terá o direito legal de se casar como homem e de ter como esposa uma verdadeira mulher. Também não sabemos se será capaz de copular: a sua capacidade de ereção é, então, ignorada. Se for capaz de copulação, as coisas ficam mais fáceis. Afinal, para a literatura jurídica a infecundidade masculina não é motivo para o divórcio. Desta forma, o médico sugere que seria mais conveniente para a paciente modificar desde já o seu estado civil para o masculino, mesmo ela sendo uma "verdadeira mulher".

2. Segunda hipótese: continuar registrada como menina. Como possui a aparência exterior de um forte menino, é bem provável que não terá atrativos sexuais para os outros homens na idade adulta. A mãe dela, inclusive, já fez a pergunta: o que faremos com o seu pênis? Em um primeiro momento, a questão parece ser simples. O sujeito possui órgãos sexuais femininos internos e uma vagina praticável. A única "anomalia" presente em seu corpo é o pênis que, se retirado, pode lhe restituir integralmente uma vida feminina regular. E foi isso foi justamente o que a mãe solicitou que os médicos fizessem.

No entanto, Ombrédanne recusa qualquer tomada de decisão precipitada. Ele afirma que não pretende realizar a cirurgia de retirada do pênis, como solicitado pela mãe da paciente. Diz que não fará nada antes da decisão do tribunal, pois mesmo com um pedido escrito pelos pais ou com um pedido escrito pelo paciente quando maior de idade, ele continuará responsável pela amputação do pênis e poderá ser condenado por castração. Ele comenta ainda que já havia observado um outro caso de hermafroditismo girandroide, de uma mulher que também possuía um corpo masculino. Neste caso, a verificação do sexo também tinha sido feita por uma laparotomia e a verificação da existência de uma vagina "praticável" tinha sido realizada por ele mesmo. A pessoa tinha o projeto de se casar como mulher, era maior de idade e a família foi consultada e advertida. Ele realizou a amputação do que chamou de "um pênis verdadeiramente esplêndido" e até chegou a apresentar o caso anos mais tarde em encontros científicos para outros cirurgiões. Acontece que nesta mesma época, ele reencontrou a mulher que lhe confessou em tons de lamento que havia se arrependido de ter feito a cirurgia. Segundo ela, o papel de mulher lhe deu muito menos satisfação do que as experiências que tinha obtido anteriormente com o seu pênis. Ombrédanne (1933) conclui o seu relato afirmando acreditar que os sujeitos possuidores de "genitais anormais" são geralmente instáveis psiquicamente, 
o que não se deve ignorar jamais. E que todas as soluções já pensadas por ele como meio-termo, como a redução do pênis com a conservação da glande, por exemplo, não garantem nenhum resultado efetivo do ponto de vista funcional.

\section{Análise da tese Le concept de troisieme genre: a propos de la décision d'um changement de sexe chez un sujet de 18 ans hermaphrodite vrai, defendida em 1984 .}

Este caso é uma dramática história de um rapaz que é identificado como hermafrodita e é convencido pela mãe e pela equipe médica a se submeter a uma cirurgia de ressignificação de sexo, mesmo contra a própria vontade. O sujeito em questão já possuía 18 anos e veio de uma cidade chamada Pointe-Noire, localizada na República do Congo. Na tese, nada é dito sobre a sua raça e/ou etnia, bem como a condição financeira de sua família. Ele foi registrado e criado como menino, com o nome de Alain-François. Seus pais eram separados desde que ele tinha 4 anos de idade, tendo sido criado pelo pai, pela madrasta, na companhia de seus irmãos e meiosirmãos. Quando chegou na puberdade, o desenvolvimento de seios e o surgimento da menstruação provocaram nele um progressivo isolamento, bem como uma recusa em sair de casa durante o dia e ir para a escola. Neste período, ele reestabelece relações com a mãe, que se prontifica a ajudá-lo, tomando a iniciativa de buscar uma solução para o problema na França. A partir deste momento, ela toma todas as providências necessárias para que o diagnóstico e tratamento seja feito em Paris. Por razões desconhecidas, o pai se opõe ao projeto de uma intervenção cirúrgica. A médica também não consegue obter muitas informações sobre a infância de AlainFrançois, já que a mãe perdeu contato com ele muito cedo e o pai não estava presente para contribuir neste sentido.

Em 29 de julho de 1983, Alain é encaminhado ao professor Luton, no Hôpital Cochin, para a análise da sua ambiguidade sexual. O exame clínico descrito na tese afirma que ele se apresenta à primeira vista como um rapaz. Sua morfologia, no entanto, é predominantemente feminina: possui uma bacia feminina, os seios são perfeitamente desenvolvidos e os pelos apresentam-se como no corpo das mulheres. Já os órgãos sexuais são descritos como "anormais" e se organizam da seguinte forma: um pequeno pênis de 5 centímetros; um arredondamento genital lateral que, ao ser apalpado, não revela a presença de testículos; um orifício de 5 milímetros que permite ao paciente urinar sentado. O cariótipo revelou se tratar de um sujeito $46 \mathrm{XX}$ e a laparoscopia, que ele possuía um útero, duas trompas, um ovário à direita e à esquerda uma pequena gônoda, que mais tarde, através de um exame citológico, descobriu-se ser um testículo atrofiado. Os exames hormonais também foram compatíveis com os de uma mulher adulta, comprovando a existência de tecido ovariano funcional. Desta forma, em função desses resultados, Alain foi diagnosticado como hermafrodita. Em sua primeira hospitalização, o médico decide pela transformação cirúrgica em 
um sentido masculinizante, já que este era o verdadeiro desejo de Alain, apesar da prevalência de características femininas em seu exame. A tese analisada transcreve as próprias palavras do médico, também transcritas aqui:

(...) o jovem François foi criado como um menino e não consegue absolutamente ser outra coisa que um menino, sendo, portanto, impensável o transformar em um sentido feminino, parecendo desejável no momento que seja bem explicado aos pais desta criança, de o transformar em um sentido masculino.7 (Garel, 1984: 5)

O projeto de masculinização proposto pelo professor Luton consistia em uma mastectomia e retirada do aparelho reprodutor feminino. $\mathrm{O}$ médico ainda chamava a atenção para o fato de que o paciente não conseguiria urinar em pé e ainda teria que passar por um processo de virilização fazendo uso de hormônios masculinos.

No entanto, quando Alain é encaminhado para o professor Bienayme, do Hôpital Saint-Vicent-de-Paul (o texto não explica as razões pelas quais houve a mudança de hospital e médico responsável), em sua segunda hospitalização, do dia 8 a 23 de agosto de 1983, a indicação acima descrita é reavaliada e modificada. Mesmo demonstrando um claro desejo de eliminar as suas características sexuais femininas (seios e menstruação), a existência de um aparelho reprodutor feminino completo faz com que a equipe médica chegue à conclusão de que não seria conveniente mutilar o que eles descrevem como "uma mulher capaz de possuir uma vida sexual normal" em função da impossibilidade de uma verdadeira transformação masculina. O acompanhamento psicológico de Alain se torna, neste momento, dramático: ele reafirma a sua identidade masculina e não aceita nenhum dos argumentos anatômicos, psicológicos e sociais elaborados pela equipe médica ou por sua mãe. Esta, por sua vez, defende de forma veemente a identidade feminina de seu filho, o que é mais um elemento que reforça o ponto de vista dos próprios médicos. Diante desta situação, o setor de psiquiatria sugere que seja concedido ao paciente um tempo para que pudesse refletir sobre as possibilidades propostas e suas implicações. É então que do dia 24 de agosto a 5 de setembro de 1983, ele passa um período no Hôpital de la Cité Universitaire, no setor de psiquiatria. Os psiquiatras mantêm neste período um contato regular com ele, que demonstra estar assustado com os pacientes ao seu redor. A inquietude diante de um ambiente tão hostil faz com que ele jamais saia do quarto e deseje voltar o quanto antes para o hospital em que deve ser operado. Com isso, o período destinado para a reflexão sobre a sua identidade sexual e as implicações de suas escolhas é encurtado.

7 (...) le jeune François a été élévé comme un garçon et n'entend absolument pas être autre chose qu'un garçon, il est donc tout à fait inenvisageable de le transformer dans un sens féminin il semble souhaitable à l'heure actuelle, ce qui a été bien explique aux parentes de cet enfant, de le transformer dans um sens masculin. 
No dia 5 de setembro Alain retorna ao Hôpital Saint-Vincent-de-Paul e ao longo desta hospitalização solicita de forma clara e determinada a intervenção cirúrgica no sentido feminino. As razões para tal mudança são descritas pela médica psiquiatra da seguinte forma:

Enfim confrontado quanto à evidência da impossibilidade de tornar-se um homem pleno, apoiado pelo desejo de sua mãe ecerto de seus novos conhecimentos sobre o seu corpo e a sexualidade, Alain solicita a intervenção, que deseja o mais rápido possível, desejo que exprime diretamente diante do senhor BIENAYME e do qual ele nos informa nesses termos: "desde que o professor BIENAYME me disse que eu não tinha testículos, eu não sou um menino". (Garel, 1984: 14)

Diante da "escolha" definitiva feita por Alain, no dia 22 de setembro acontece a primeira intervenção cirurgica: a retirada da gônoda esquerda que revelou-se ser um testículo atrofiado. Logo depois, no dia 4 de outubro, há o aterramento e redução do clitóris. Segundo o relato, o resultado plástico final ficou perfeitamente satisfatório, com exceção da cavidade vaginal pouco ampla, que precisaria provavelmente de dilatações posteriores. Quanto aos aspectos psicológicos pós-operatórios, principal objetivo da tese analisada, há alguns aspectos muito interessantes para o nosso trabalho. Acompanhado diariamente tanto pela equipe de psicólogos como de psiquiatras, Alain - que tornou-se Aline após a mudança de sexo - mostrava-se constantemente "mudo, fechado, isolado em seu quarto, respondendo as questões feitas por sim ou não com tempo de latência muito longo". O diagnóstico de esquizofrenia foi logo descartado, sendo atribuído tal comportamento ao seu limitado conhecimento da língua francesa.

Com o tempo, ele ${ }^{9}$ desenvolve uma discreta curiosidade em relação aos elementos femininos, interrogando sobre as vestimentas, o cabelo e os cuidados com a higiene específicos de seu novo gênero. Depois da intervenção cirúrgica surgem também as projeções para o futuro, completamente bloqueadas até então. É demonstrado o desejo de retornar ao seu país, de rever a família, de aprender uma profissão. Paralelamente a isso, a equipe observa o surgimento de um comportamento depressivo intenso, correspondendo a apreensão da realidade com todas as suas consequências. Alain expressa neste momento sua apreensão quanto ao lugar que ele poderá ter dentro da sociedade adolescente local, seu medo das

8 Enfin, afronté à une évidence quant à l'impossibilité de devenir un homme à part entière, soutenu par le désir de as mère et fort de ses connaissances nouvelles sur son corps et la sexualité, Alain en vient à demander l'intervention, la souhaitant le plus rapidement possible, désir qu'il exprime directement auprés de monsieur BIENAYME et dont il nous fait part en ces termes: "puisque le Professeur BIENAYME m’a dit que je n'avais pas de testicules, je ne suis pas um garçon".

9 A partir desse momento, a tese de Garel passa a utilizar o pronome "ela" para referir-se a Alain/Aline. Aqui continuaremos utilizando o pronome masculino "ele" em sintonia com o gênero com o qual Alain de fato se identificava. 
zombarias e da rejeição, a impossibilidade de imaginar seu comportamento com os meninos. Sua insatisfação se fixa em um detalhe da cicatriz ao nível do clitóris, que toma uma importância tida pela médica como excessiva. $\mathrm{O}$ comportamento depressivo é dissipado próximo da sua partida e retorno ao Congo, com um período de transição na casa de uma prima na cidade de Brazzaville, em um ambiente onde os seus problemas seriam ignorados. Ele deveria aproveitar este tempo para adquirir uma formação profissional, bem como para se beneficiar do apoio de uma assistência social local.

Quando em 1984 Garel envia uma carta para Alain para ter notícias do seu projeto de reintegração social e profissional, a resposta recebida não é exatamente a esperada. Ele diz que se sente abandonado e inativo. Privado do apoio esperado, os efeitos da depressão são aparentes. No entanto, a escolha pela mudança de sexo parece não ser colocada em questão. Ele pede, inclusive, que ela lhe envie saias e vestidos, já que não é mais o seu desejo vestir calças. Por fim, a médica lamenta a situação e diz estar a procura de ajuda psicológica para ajudar o seu antigo paciente, que demonstra estar em um situação de grande fragilidade emocional. Analisando a tese, não podemos afirmar categoricamente que a depressão de Alain/Aline devese apenas à sua mudança de sexo não desejada. Contudo, podemos deduzir que esta hipótese é bem plausível, já que desde o início ele demonstrou o seu desejo de retirar os seios e acabar com a menstruação, preservando a sua identidade masculina.

\section{Considerações finais}

Vimos que até o início do século XIX, a regulação dos corpos intersexuais estava sob responsabilidade dos legisladores e juízes que, em algumas situações, solicitavam conselhos aos médicos ou padres. Ainda no século XIX, a medicina ocupou este espaço. Iniciando-se com a "era das gônodas", o saber biomédico desenvolveu a partir daí novas tecnologias que buscavam oferecer as ferramentas necessárias para a "readequação" dos corpos que aqui chamamos de "indecidíveis". Felizmente, a partir do final da década de 1980, as numerosas pesquisas em Filosofia e nas Ciências Humanas desenvolveram novas teorizações no campo dos estudos de gênero. Pouco a pouco, destacou-se a evidência da historicidade do sexo, abalando a ideia de que existe um suposto corpo natural. Em Problemas de gênero: feminismo e subversão da identidade, livro publicado em 1990 e talvez o texto mais influente da teoria queer, Butler (2013) afirma que o construto chamado "sexo" é tão culturalmente construído quanto o gênero. Apesar de tal afirmação ter sido fundamental para pensarmos o gênero e o corpo enquanto construções sociais, é importante chamar a atenção para o fato de que a própria Butler reconsidera tais afirmações 24 anos depois. Na entrevista Judith Butler addresses TERFs and the work of Sheila Jeffreys and Janice Raymond (2014), Butler revê as suas teorias publicadas no início dos anos de 1990 sobre a performance de gênero a partir das demandas trans. Ela afirma que 
nunca teve a intenção de defender o gênero como uma completa ficção. De acordo com as suas próprias palavras,

Não pretendi argumentar que o gênero é fluido e mutável (o meu certamente não é). Eu só queria dizer que todos devemos ter maiores liberdades para definir e seguir nossas vidas sem patologização, desrealização, assédio, ameaças de violência, violência e criminalização. Entro na luta para realizar um mundo assim..$^{10}$ (Butler: 2014)

Também ganhou força na década de 1980 os movimentos políticos liderados por pessoas intersexuais que passaram por cirurgias quando crianças e, já na idade adulta, passaram a contestá-las. Tais narrativas em primeira pessoa surgiram como um desafio ao saber/poder biomédico. Os ativistas passaram a reivindicar autonomia em relação à decisão sobre a realização das cirurgias e escolha do sexo, sendo contrários à realização de cirurgias em neonatos e crianças pequenas quando o caso não oferecesse riscos à saúde. No entanto, até hoje, as principais práticas de gestão da intersexualidade por parte da medicina continuam sendo a indicação cirúrgica e o tratamento hormonal em bebês para eliminar qualquer tipo de ambiguidade no fenótipo de sua genitália e sua suposta identidade de gênero. A realização imediata das cirurgias e tratamentos hormonais são vistos pelos médicos, de maneira geral, como forma de garantir o bem-estar psicossocial da criança, sendo assim um dever moral dos pais. Não por acaso uma das principais hipóteses de Machado (2008) para a adoção do termo "Distúrbios do Desenvolvimento Sexual" por parte da classe médica, em 2006 no "Consenso de Chicago", seria o desejo da comunidade médica em afastar-se do movimento político intersex, sobretudo norte-americano, e às questões que este vem colocando às intervenções médicas sobre os corpos dos sujeitos intersexuais desde a década de 1990.

No presente artigo, através da análise de alguns casos de intersexualidade ocorridos nos séculos XIX e XX na França, mostramos como o saber médico se apoderou e controlou os corpos que não conseguiam ser enquadrados no sistema binário homem-mulher. Importante ressaltar que os documentos aqui expostos são cronologicamente anteriores tanto ao surgimento dos estudos de gênero queer, quanto dos movimentos sociais intersex. Desta forma, podemos perceber com mais clareza como os corpos intersexuais foram controlados pelo saber/poder médico a partir do século XIX e ao longo do século XX. Iniciamos nossa investigação com o caso de Herculine Barbin, apresentado por Foucault. Através de uma história narrada em primeira pessoa, vimos como Alexina, nascida em 1838 na França, foi reconhecida na idade adulta como um "verdadeiro" rapaz e, por isso, submetida a um tribunal

10 I did not mean to argue that gender is fluid and changeable (mine certainly is not). I only meant to say that we should all have greater freedoms to define and pursue our lives without pathologization, de-realization, harassment, threats of violence, violence, and criminalization. I join in the struggle to realize such a world. 
para devolver-lhe ao seu "verdadeiro" sexo. Interessante notar como este caso ilustra a passagem do olhar jurídico para o olhar médico no século XIX em relação aos casos de intersexualidade: ela foi obrigada a mudar o seu sexo legal através de um processo jurídico compulsório após ser diagnosticada como hermafrodita e depois, após a sua trágica morte, teve o corpo escrutinado pelo saber médico. Vimos também que, na mesma época, Nadar provavelmente foi o primeiro fotógrafo a registrar a imagem de um corpo intersexual. Enquanto a mudança de sexo de Alexina ocorre em 1860, as fotos de Nadar datam de janeiro de 1861. Ombrédanne, por sua vez, ainda na primeira metade do século XX e antes da "era das cirurgias", realiza uma laparotomia em uma jovem intersexual também para descobrir o seu "verdadeiro" sexo. Mesmo não promovendo uma cirurgia de ressignificação sexual - afirma, inclusive, ser esta uma decisão precipitada no caso analisado, apesar dos apelos da mãe da jovem para realizá-la - ele submete a paciente a uma cirurgia que poderia colocar a sua vida em risco. E o último caso analisado neste artigo, ocorrido já na segunda metade do século $\mathrm{XX}$, há uma cirurgia de ressignificação sexual: Alain, um jovem que foi criado como menino e identificava-se com o sexo masculino, é diagnosticado como intersexual e convencido pela mãe e pela equipe médica a tornar-se uma mulher. Mesmo com uma morfologia predominantemente feminina, o seu desejo era continuar pertencendo ao sexo masculino. Vimos como tal transição provocou no rapaz um comportamento melancólico, que o levou provavelmente ao quadro de depressão observado pela psiquiatra que escreveu a tese em questão.

Os casos analisados neste artigo, pensados a partir de um distanciamento histórico considerável, parecem hoje algo muito distante de uma realidade de pensamento pautada pela desconstrução do sujeito. No entanto, na prática cotidiana, faz-se ainda necessárias algumas investigações e críticas em relação à maneira como ainda pensamos os sujeitos generificados. Segundo Fausto-Sterling (1993), a cultura ocidental é profundamente comprometida com a ideia da existência de apenas dois sexos. $\mathrm{O}$ pressuposto que, sem cuidados médicos, os sujeitos intersexuais estariam condenados a uma vida miserável tornou-se rapidamente um dogma científico, sem muitos estudos empíricos para corroborá-lo. O desenvolvimento tecnológico no campo biomédico alcançado nas últimas décadas permite aos médicos identificar a maioria dos sujeitos intersexuais no momento do seu nascimento, sendo, desta forma, quase imediata a entrada dessas crianças em programas de controle hormonal e cirúrgico para que elas possam viver na sociedade como machos e fêmeas "normais". É importante ressaltar que as metas desta política são genuinamente humanitárias, refletindo o desejo da comunidade médica de que essas pessoas possam se "encaixar" tanto física quanto psicologicamente em um mundo pautado pela existência de apenas dois sexos, como também pela heterossexualidade. Segundo Machado (2005:70-71): "As técnicas cirúrgicas são empregadas no sentido de tornar a genitália da criança "o mais próximo possível do normal”, de acordo com determinados padrões de tamanho, forma, terminação do trajeto urinário e uso". Quanto ao uso, podemos verificar que o objetivo continua tendo em vista as práticas sexuais heteronormativas: neste caso, construir vaginas "penetráveis" e pênis "que penetrem". 
Por fim, expressamos aqui a necessidade de pensarmos em outras possibilidades de existência onde os sexos possam ser multiplicados para além dos limites atualmente imagináveis. E não apenas para pensarmos a questão dos sujeitos intersexuais, mas também para pensarmos os corpos generificados dos sujeitos nascidos biologicamente "normais". Afinal, se levarmos em conta as esferas psicológica, anatômica e cromossômica dos indivíduos, existem bem mais do que apenas dois sexos.

\section{Agradecimentos:}

Coordenação de Aperfeiçoamento de Pessoal de Nível Superior (CAPES), Universidade Federal do Estado do Rio de Janeiro (UNIRIO) e Instituto Federal do Rio de Janeiro (IFRJ).

\section{Referências}

BARBIN, Herculine. (1982). "Minhas memórias". In. FOUCAULT, Michel. Herculine Barbin: o diário de um hermafrodita / Apresentação de Michel Foucault. $1^{\mathrm{a}}$ edição. Rio de Janeiro: Francisco Alves, pp. 11-105.

BUTLER, Judith. (2013). Problemas de gênero: feminismo e subversão da identidade. $1^{\mathbf{a}}$ edição. Rio de Janeiro: Civilização Brasileira.

BUTLER, Judith. (2014). "Judith Butler addresses TERFs and the work of Sheila Jeffreys and Janice Raymond. Entrevista concedida a Cristian Williams". The TERFs. London, May 1. Diponível em: http://theterfs.com/2014/o5/o1/judith-butleraddresses-terfs-and-the-work-of-sheila-jeffreys-and-janice-raymond/. Acesso em: 10/08/2020.

CHESNET, Hippolyte. (1982). "Question d'identité. Vice de conformation des organes génitaux. Hypospadias. Erreur sur le sexe”. In. FOUCAULT, Michel. Herculine Barbin: o diário de um hermafrodita / Apresentação de Michel Foucault. $\mathbf{1}^{\mathbf{a}}$ edição. Rio de Janeiro: Francisco Alves Editora, pp. 115-118.

DORLIN, Elsa. (2008). Sexe, genre et sexualités. $1^{\mathrm{a}}$ édition. Paris: Presses Universitaires de France.

FAUSTO-STERLING, Anne. (1993). "The five sexes: why male and female are not enough”. The sciences. New York, March/April, pp. 20-25. 
FAUSTO-STERLING,Anne(2000). Sexing the body: gender politics and the construction of sexuality. $1^{\underline{a}}$ edition. Nova York: Basic Books.

FOUCAULT, Michel. (1982). Herculine Barbin: o diário de um hermafrodita / Apresentação de Michel Foucault. $\mathbf{1}^{\mathrm{a}}$ edição. Rio de Janeiro: Francisco Alves Editora.

FOUCAULT, Michel. (2010). Os anormais: curso no Collège de France (1974-1975). 2 $2^{\underline{a}}$ edição. São Paulo: WMF Martins Fontes.

GAREL, Patricia Blanche. (1984). "Le concept de troisieme genre: a propos de la décision d'un changement de sexe chez um sujet de 18 ans hermaphrodite vrai". Tese (Doutorado em Medicina) - Faculté de Medecine Necker - Enfants Malades, Université Paris V René Descartes, Paris, brochura.

GAUDENZI, Paula. (2018). "Intersexualidade: entre saberes e intervenções”. Cadernos de Saúde Pública [online], Rio de Janeiro, Vol. 34, n. 1, pp. 1-11.

GOUJON, Étienne. (1869). Étude d'um cas d'hermaphrodisme bisexuel imparfait chez l'homme. Paris: Imprimerie de E. Martinet. Disponível em: http://gallica.bnf.fr/ ark:/12148/bpt6k64594407/f7.image. Acesso em: 18 set. 2017.

HOUBRE, Gabrielle. (2009). "Um sexo impensável: a identificação dos hermafroditas na França do século XIX”. Trad. Débora El-Jaick de Andrade. Revista Espaço Plural, Cascavel, Ano X, n. 21, pp. 20-30.

LAQUEUR, Thomas. (2001). Inventando o sexo. Corpo e gênero dos gregos a Freud. $1^{\text {a }}$ edição. Rio de Janeiro: Relume Dumará.

LE MENS, Magali; NANCY, Jean-Luc. (2009). L’hermaphrodite de Nadar. $1^{\mathrm{a}}$ édition. Nantes: Creaphis Éditions.

MACHADO, Paula Sandrine. (2005). "Quimeras da Ciência: a perspectiva de profissionais da saúde em casos de intersexo". Revista Brasileira de Ciências Sociais, São Paulo, Vol. 20, n. 59, pp. 67-80.

MACHADO, Paula Sandrine. (2008). "Intersexualidade e o consenso de "Chicago". As vocissitudes da nomenclatura e suas implicações regulatórias". Revista Brasileira de Ciências Sociais, São Paulo, Vol. 23, n. 68, pp. 109-123.

MACIEL-GUERRA, Andréa T. \& GUERRA-JÚNIOR, Gil. (2005). "Intersexo: entre o gene e o gênero”. Arquivo Brasileiro de Endocrinologia e Metabolismo, São Paulo,Vol. 49, n. 1, pp. 1-3. 
OMBRÉDANNE, Louis. (1933). Hermaphrodite gynandroîde parfaite: une jeune fille dans une situation difficile. $1^{\underline{a}}$ édition. Paris: Masson et Cle Éditeurs.

PINO, Nádia Perez. (2007). "A teoria queer e os intersex: experiências invisíveis de corpos des-feitos". Cadernos Pagu, Campinas, n. 28, pp. 149-174.

TARDIEU, Ambroise. (1874). Question médico-légale de l'identité dans ses rapports avec les vices de conformation des organes sexuels. $1^{\underline{a}}$ édition. Paris: Librairie J. B. Baillière et Fils.

Recebido em 01/o9/2019.

Aceito em 14/o8/2020. 